MedieKultur | Journal of media and communication research | ISSN 1901-9726

Article - Theme section

\title{
Cultural journalists on social media
}

\section{Nete Nørgaard Kristensen \& Unni From}

MedieKultur 2018, 65, 76-97

Published by SMID | Society of Media researchers In Denmark | www.smid.dk

The online version of this text can be found open access at https://tidsskrift.dk/mediekultur

\begin{abstract}
This article investigates the use of social media among a particular group of journalists: cultural journalists. Combining research on social media journalism with research on cultural journalism and applying a mixed-methods approach, the study shows that use of social media is still a fairly random practice in cultural newsrooms. It also shows that cultural journalists use their Twitter and Facebook accounts interchangeably as tools for professional communication in their daily work and for personal communication in their daily lives. In other words, their social media practices blur the boundaries between institutional interests and professional identities, and more private interests and personal identities. While this may be a challenge to most journalists, it resonates well with the professional logics of cultural journalists. They have long practiced their work in a grey-zone between the public and the private, and the objective and subjective. Through their social media practices, they promote the media institution they work for and their own 'personalised' professional brand.
\end{abstract}

\section{Keywords}

Cultural journalism, Cultural journalists, Facebook, Public self, Self-branding, Social Media, Twitter 


\section{Introduction}

Research on journalists' use of social media, especially Twitter, is an explosively growing field in journalism studies. A main focus has been on news journalists and political journalists, while fewer studies have examined journalists from particular beats, such as arts and culture. This article aims to remedy this void by analysing how Danish cultural editors think strategically about the use of social media in the cultural newsroom, and how selected cultural journalists actually use social media. This is important because the professional logics of this beat, especially the priority given to opinionated approaches and personal style, seem to fit well with the logics of social media. The article combines research on journalists' use of social media (e.g., Brems et al., 2016; Canter, 2013, 2015; Hanusch \& Bruns, 2017; Hedman \& Djerf-Pierre, 2013, 2017; Hermida, 2010, 2013, 2017; Vis 2013) with theoretical and empirical research on cultural journalists as a professional group (e.g., Forde, 2003; Jaakkola, 2015; Kristensen \& From, 2015a; Kristensen \& Riegert, 2017). Methodologically, the study applies a mixed-methods approach: Qualitative interviews with Danish cultural editors establish the strategic use of social media in Danish cultural newsrooms, while a quantitative mapping of selected Danish cultural journalists' Twitter and Facebook communication outlines the broader contours of this communication, illustrated by qualitative examples.

The article consists of five sections. First, we outline the main findings of recent research on journalists' use of social media. Second, we present a theoretical framework for understanding cultural journalists as "journalists with a difference" (Forde, 2003) in view of the particular professional logics that characterise this beat. Third, we present the mixed-methods design of our study, and, finally, we outline our analytical findings. They suggest that use of social media is still a fairly random practice in cultural newsrooms and among cultural journalists in Denmark, even though the logics of social media fit well with their professional ethos. Furthermore, we show that this practice is characterised by quite blurred boundaries between the journalists' institutional interests and professional identities and their more private interests and personal identities. The study suggests that cultural journalists gain authority by association to particular news organisations, which provide them with public legitimacy and voice within institutionalized frameworks. At the same time, the individual cultural journalist brands the media institution by means of his or her personalized professional image and style of communication.

\section{Research context: Journalists on social media}

Since the early 2010s, we have seen two important focus areas in the rapidly growing research on journalists' use of social media. One area focuses on journalists' use of social media for professional (institutional) purposes, and another focuses on journalists' use of social media for self-branding (individual) purposes. 
The first strand of research investigates how social media are integrated in and changing the professional practices of journalists. This research takes the news institution and the professional norms, values and routines of journalists as a starting point (e.g., Hermida, 2013) and draws some of the same conclusions: The use of social media is becoming an increasingly "normalized" professional practice (Lasorsa, Lewis \& Holton, 2012), adjusted to the existing norms and routines of journalism. Social media, such as Twitter, have become a means of newsgathering, finding sources/crowdsourcing, breaking and distributing news, and interacting with audiences (e.g., Hermida, 2010, 2013, 2017; Parmelee, 2013; Vis, 2013). At the same time, social media influence and transform the professional norms and routines of journalism, such as objectivity, gatekeeping and sourcing, as features from "outside the field of established journalism" (Hermida, 2013, p. 298) are adopted. This is because social media are primarily means of user-centred communication of everyday life (Lomborg, 2014) or of online self-communication (van Dijck, 2013, p. 11).

A second strand of research looks at how professional journalists use social media for self-branding purposes. That is, purposes that link less to the news institution and more to the individual journalist in an increasingly precarious labour market and in a media culture where personal branding, or "the proliferation of the public self" (Marshall, 2014), via social media is a new normal. Brems et al. (2016) point out that "The Self" has become a tool for journalists on social media, resulting in four dilemmas between "broadcasting information and interacting; remaining factual and being opinionated; sharing personal information and remaining professional; and promoting the self in an implicit or explicit way" (Brems et al., 2016, p. 13). Hanusch and Bruns (2017) argue that journalists engage in these social media self-branding endeavours to gain economic and social capital. Tandoc and Vos (2016) claim that journalists have become marketers of their own work on social media - and of themselves, it could be argued. Barnard (2016, p. 203) even argues that journalists are now normalized into the hybrid relationship between traditional journalistic practices and digital media practices, as these practices increasingly converge. Taking the argument a step further, Molyneux (2015) concludes that journalists essentially relinquish their professional roles as gatekeepers and information gatherers on social media, because they accommodate to the social media logic by passing "along a mix of opinion, humor, and personal branding" (Molyneux, 2015, p. 932). They do this in order to form relationships with audiences and to cultivate their self-interests.

Using Twitter as a case, Canter (2013) captures these two strands of research when distinguishing between two channels of communication on social media with "a traditional function for news organizations and a social function for journalists" (Canter, 2013, p. 492). Furthermore, she identifies four specific Twitter utilities for journalists: news gathering, live 'reporting', building of personal brands, and company branding. In line with Molyneux (2015), she emphasises how these Twitter practices "have seen journalists begin to cross the historic line between the professional and the personal, the objective and the subjective" (Canter, 2015, p. 890). 
Most studies focus on news journalists and political journalists, while fewer analyse how journalists from specialised beats use social media. ${ }^{2}$ Just as employment status (permanent staff/freelance) may influence social media use (see, for example, Brems et al., 2016; Carpenter, Kanver \& Timmons, 2016), beat specific features may affect these performances. Based on a sample of Swedish journalists, Hedman and Djerf-Pierre (2017) show that journalists specialised in opinionated journalism (writing editorials, commentaries etc.) are most active on Twitter compared to other types of journalists. When speaking of a "normalization" of journalistic practices to social media logics, it is thus important to be sensitive to what the "normal practices" of the beat are. ${ }^{3}$ Arts and cultural journalism, for example, has historically been characterised by not conforming to the traditional logics of journalism. This potentially makes the conclusions of existing research less representative of this beat.

\section{Theory: The specialised practices of cultural journalists}

International research applies a number of often overlapping terms to designate the journalists at the center of this article. "Cultural journalist" is used here as it has become an increasingly common term in recent scholarship (e.g., Golin \& Cardoso, 2009; Heikkilä, Lauronen \& Purhonen, 2017; Jaakkola, 2015; Kersten \& Janssen, 2017; Kristensen \& From, 2015a; Kristensen \& Riegert, 2017). It is an umbrella term for journalists who report on, review and debate culture, including the arts, popular culture, the culture industries, entertainment, lifestyle and value politics. Cultural journalists are said to be "journalists with a difference" (Forde, 2003) because their professional background and terms of employment, their role perceptions and their actual journalistic practices differentiate them from other types of journalists. These differences potentially influence their use of social media.

The first difference is related to the training of cultural journalists. Expertise within a particular aesthetic field, e.g., music, literature or film, has historically been viewed as a prerequisite to be able to write about such topics with professional authority (e.g., Hovden \& Knapskog, 2015; Jaakkola, 2015). Cultural journalists are therefore often trained in arts and humanities rather than journalism. Empirical research has shown that cultural journalists perceive themselves as better educated than other journalists (e.g., Harries \& Wahl-Jorgensen, 2007; Hovden \& Knapskog, 2015), and they do, in fact, have more or a higher level of education than other types of journalists (Hovden \& Kristensen, 2018). This has provided them with a mindset that focuses on aesthetic norms and values rather than news values, suggesting that cultural journalists tend to have one leg in academia and another in journalism (Kristensen \& From, 2015b). This guides their journalistic practices but potentially also their use of social media.

A second difference relates to the long tradition of less job security and stability in cultural journalism compared to other beats. Many cultural journalists work freelance and 
have loose media institutional couplings. Even today, a larger share of cultural journalists have non-permanent positions and work part-time compared to other types of journalists (Hovden \& Knapskog, 2015; Hovden \& Kristensen, 2018). Self-branding and proliferating the public self on social media may thus be particularly important to cultural journalists in this increasingly precarious job market.

A third aspect suggesting that cultural journalists are "journalists with a difference" connects to the role that cultural journalists play in the public realm. The theoretical literature has argued that cultural journalists perform the role of cultural mediator mediating between cultural producers and cultural consumers (Bourdieu, 1984; Janssen \& Verboord, 2015). This mediator role includes serving as: a cultural gatekeeper by bringing attention to selected cultural topics and goods while neglecting others; networker, as cultural journalists are often closely intertwined with artists and cultural producers through close collegial collaborations or even friendship-like relations (Forde, 2003; Kristensen, 2003, 2017); marketer, since media coverage is also publicity for artists and cultural goods; and legitimizer of "good culture", as journalists' and critics' evaluative debates may raise the esteem of cultural products or even sub-fields in the cultural hierarchy (Baumann, 2001; Sparre \& From, 2017). Accordingly, the traditional roles of monitoring elites, setting agendas and informing citizens' political decision-making are less central to cultural journalists. This would suggest that some of the professional dilemmas of social media logics, pointed to by the international literature, are perhaps less challenging for cultural journalists, e.g., whether to disseminate information or promote goods, be factual or opinioned, be professional or personal, etc.

A fourth difference, which is closely related to the three mentioned above, concerns how cultural journalists practice their work, i.e., how they approach the topics they write about in terms of genres and style. Critical and literary genres, such as reviews, features, essays or commentaries, are more prominent in cultural journalism than in other types of journalism, and personality and a distinct style are allowed for, if not expected (Chong, 2017; Jørgensen, 2007). The journalists' personal motivation, cultural interest or expertise often become agenda-setting for specific news media's coverage of art and culture (Kristensen \& From, 2011). Furthermore, cultural journalists tend to have more freedom to choose stories (Hovden \& Knapskog, 2015) and are under less production pressure than other journalists (Hovden \& Kristensen, 2018). Thus, newsroom constraints are perceived as being less severe.

For these numerous reasons, scholars apply terms such as "arts exceptionalism" (Harries \& Wahl-Jorgensen, 2007) and "aesthetic paradigm" (Hellman \& Jaakkola, 2012) to designate the particularity of cultural journalists. Although scholars also speak of a "newsification" or "journalistification" of cultural journalism (Jaakkola, 2015; Sarrimo 2016), referring to cultural journalists becoming more like news journalists, these main characteristics remain strong and may explain why cultural journalists are "journalists with a difference" (Forde, 2003). 
Taking this difference as point of departure, we in the following analyse cultural editors' strategic considerations about social media in the cultural newsroom as well as the actual performances of cultural journalists on social media. Whereas the role of promoter is foreign to most Western journalists, being a mediator between cultural producers and cultural audiences/users is key to cultural journalists. Similarly, the blending of news and views afforded by social media may challenge the norms of traditional news journalists, such as facticity, source criticism and neutrality, but this challenge is potentially less evident to cultural journalists. Their journalistic turf has long been distinguished by opinionated genres, by journalists and critics building personal brands based on their specific review and commentary style, and by a blurring of the professional and personal. This would suggest that cultural journalists potentially navigate the dilemmas pointed to by Brems et al. (2016) more easily than other types of journalists or with less normative constraints. Put differently, the blurring of boundaries on social media between the public and private potentially comply better with the logics of cultural journalists.

\section{Methodology: A mixed-methods approach}

Research on journalists' use of social media has been dominated by large-scale quantitative research (Hanush \& Bruns, 2017), primarily based on content analysis. These studies have aimed at mapping the new landscape for journalistic production and communication practices, using large data sets. Relatively few qualitative studies have been conducted (Molyneux, 2015). In this article, we apply a mixed-methods approach. We use data from a qualitative interview study among cultural editors to establish the strategic use of cultural journalists' social media performances in Danish newsrooms. This is combined with a quantitative coding and qualitative examples of use of social media in selected cases.

\section{Interview data}

In 2016 and 2017, we conducted nine interviews with cultural editors from leading Danish news institutions, six from newspapers (published in both print and online), and three from the Danish public service broadcasting company $D R$ (television, radio and web), see table 1. They represent different institutional ways of prioritizing cultural content. Some media prioritise cultural news and coverage highly, for example, the national newspaper Politiken and the public service institution DR. At other news media, culture in the traditional sense is not a main focus, for example, the tabloid Ekstra Bladet and the niche business paper Børsen. The overall aim of the data collection was to map how the editors conceptualize cultural journalism, in general, and cultural critique, more specifically, within their specific professional and organisational settings. Here we only include their reflections on the strategic potential and actual use of social media platforms for institutional branding and circulating cultural content. ${ }^{4}$ 


\begin{tabular}{|c|c|c|}
\hline & Media institution & Position at time of interview \\
\hline Flemming Hedegaard & DR K (public service TV channel) & Head of channel \\
\hline Ida Holten Ebbesen & DR (public service broadcaster) & Cultural editor (across platforms) \\
\hline $\begin{array}{l}\text { Morten Thomsen } \\
\text { Højsgaard }\end{array}$ & DR (public service channel) & $\begin{array}{l}\text { Editor of History and Religion } \\
\text { (across platforms) }\end{array}$ \\
\hline David Turner & Jyllands-Posten (national newspaper) & Literature editor \\
\hline Lars Rix & Berlingske (national newspaper) & Cultural editor \\
\hline Michael Solgaard & Børsen (business newspaper) & Cultural editor \\
\hline Peter Sloth & Ekstra Bladet (tabloid) & Entertainment editor \\
\hline Anna von Sperling & Information (niche newspaper) & Constituted cultural editor \\
\hline Rune Lykkeberg & Politiken (national newspaper) & Cultural editor \\
\hline
\end{tabular}

Table 1: Interviewed cultural editors

\section{Studying Facebook and Twitter activities}

There is an inclination towards studying Twitter in contemporary research on journalists' use of social media because it is a publicly open social network site, overrepresented by journalists. Social networking sites included in this study are Twitter and Facebook. Compared to the US, Twitter is not a broadly distributed social networking service in Denmark (The Danish Agency for Culture, 2016). Twitter is still interesting for this study, though, because journalists are among the most active and popular Danish Twitter users. Facebook was chosen because it is the most used social media platform in Denmark and preferred among Danes who use only one social media platform (The Danish Agency for Culture, 2016, 2017). We have only included content from public Facebook pages. Since only two cases had Facebook content open to the public, most data are from Twitter. This is paradoxical, of course, and a shortcoming of the study. In the analysis, we do not emphasise differences between Twitter and Facebook use.

\section{Sampling of cases}

Defining who today's cultural journalists are is complex because of the many terms used about this professional group: cultural journalists, reporters, critics, reviewers, etc. This complexity is a consequence of cultural journalists having "the cultural field" (Bourdieu, 1984; Knapskog \& Larsen, 2008, p. 11) as their object of reporting and scrutiny. In this study, cultural journalists are defined as editors, journalists or critics, employed (and paid) by a Danish news institution to edit, write about and/or review art and culture, either on a permanent or freelance basis. 
Scholars tend to select atypical cases when analysing journalists' social media use, e.g., very active or popular cases (e.g., Hermida, 2013, p. 299). It is often most interesting to analyse such first-movers, although level of activity or popularity reveals very little information about the resonance of their communication. Our sample includes journalists exemplifying very engaged users and less frequent users. The purposive sampling process was two-phased. After an explorative browsing of Facebook and Twitter, using the Danish terms for "cultural journalist", "reviewer", "critic" and the title of Danish news institutions, we made a selective archiving (Brügger, 2011; Lomborg, 2014) of seven cases. These cases displayed regular social media activities in the months before the sampling, i.e., a certain level of activity. Table 2 provides an overview of the cases, which all self-identify as "film critic", "film journalist", "cultural journalist", "literary critic", "cultural editor" or "reviewer". Thus, they use related albeit different titles to position themselves professionally. All list these professional titles before more personal information about their (cultural) interests, which signals the primacy of their professional identity.

The seven cases are not representative of all Danish cultural journalists on Twitter and Facebook, but they are indicative of various forms of activity and patterns of communica-

\begin{tabular}{|c|c|c|c|c|}
\hline Case & $\begin{array}{l}\text { Media affiliation } \\
\text { at time of sampling }\end{array}$ & $\begin{array}{l}\text { Position at time } \\
\text { of sampling }\end{array}$ & $\begin{array}{l}\text { Activities during } \\
\text { sample period }\end{array}$ & $\begin{array}{l}\text { Followers at time } \\
\text { of sampling }\end{array}$ \\
\hline $\begin{array}{l}\text { Christian } \\
\text { Monggaard }\end{array}$ & $\begin{array}{l}\text { Information } \\
\text { (niche newspaper) }\end{array}$ & $\begin{array}{l}\text { Film editor, critic } \\
\text { and journalist }\end{array}$ & 303 tweets & $\begin{array}{l}\text { Followers: } 36.500 \\
\text { Tweets: } 75.300\end{array}$ \\
\hline Ditte Giese & $\begin{array}{l}\text { Politiken } \\
\text { (national newspaper) }\end{array}$ & Cultural journalist & $\begin{array}{l}72 \text { tweets } \\
23 \text { Facebook posts }\end{array}$ & $\begin{array}{l}\text { Twitter } \\
\text { Followers: } 10.300 \\
\text { Tweets: } 7.999 \\
\text { Facebook } \\
\text { Followers: } 4.728\end{array}$ \\
\hline Per Lysholt & $\begin{array}{l}\text { Radio24Syv } \\
\text { (public service radio) }\end{array}$ & Cultural journalist & 46 tweets & $\begin{array}{l}\text { Followers: } 780 \\
\text { Tweets: } 4.752\end{array}$ \\
\hline Torben Sangild & $\begin{array}{l}\text { Zetland } \\
\text { (digital native news } \\
\text { medium) }\end{array}$ & $\begin{array}{l}\text { Cultural journalist, } \\
\text { radio host and } \\
\text { critic }\end{array}$ & $\begin{array}{l}14 \text { tweets } \\
18 \text { Facebook posts }\end{array}$ & $\begin{array}{l}\text { Twitter } \\
\text { Followers: } 2.927 \\
\text { Tweets: } 1.434 \\
\text { Facebook } \\
\text { Followers: } 5.648\end{array}$ \\
\hline $\begin{array}{l}\text { Sophie Engberg } \\
\text { Sonne }\end{array}$ & $\begin{array}{l}\text { Politiken } \\
\text { (national newspaper) }\end{array}$ & Literature critic & 15 tweets & $\begin{array}{l}\text { Followers: } 748 \\
\text { Tweets: } 688\end{array}$ \\
\hline Lars Rix & $\begin{array}{l}\text { Berlingske } \\
\text { (national newspaper) }\end{array}$ & Cultural editor & 14 tweets & $\begin{array}{l}\text { Followers: } 907 \\
\text { Tweets: } 1729\end{array}$ \\
\hline $\begin{array}{l}\text { Jacob Wendt } \\
\text { Jensen }\end{array}$ & $\begin{array}{l}\text { Berlingske } \\
\text { (national newspaper) }\end{array}$ & Film critic & 14 tweets & $\begin{array}{l}\text { Followers: } 2303 \\
\text { Tweets: } 2940\end{array}$ \\
\hline
\end{tabular}

Tabel 2: Selected cases 
tion. The sample mirrors the "long tail" distribution characteristic of much internet use (figure 1). Few cases are very active, accounting for a disproportionally large share of the total number of tweets/posts, while the majority is much less active. This echoes Hedman and Djerf-Pierre's (2017, p. 419) sample of Swedish journalists showing that even though many journalists have a Twitter account, few are very active.

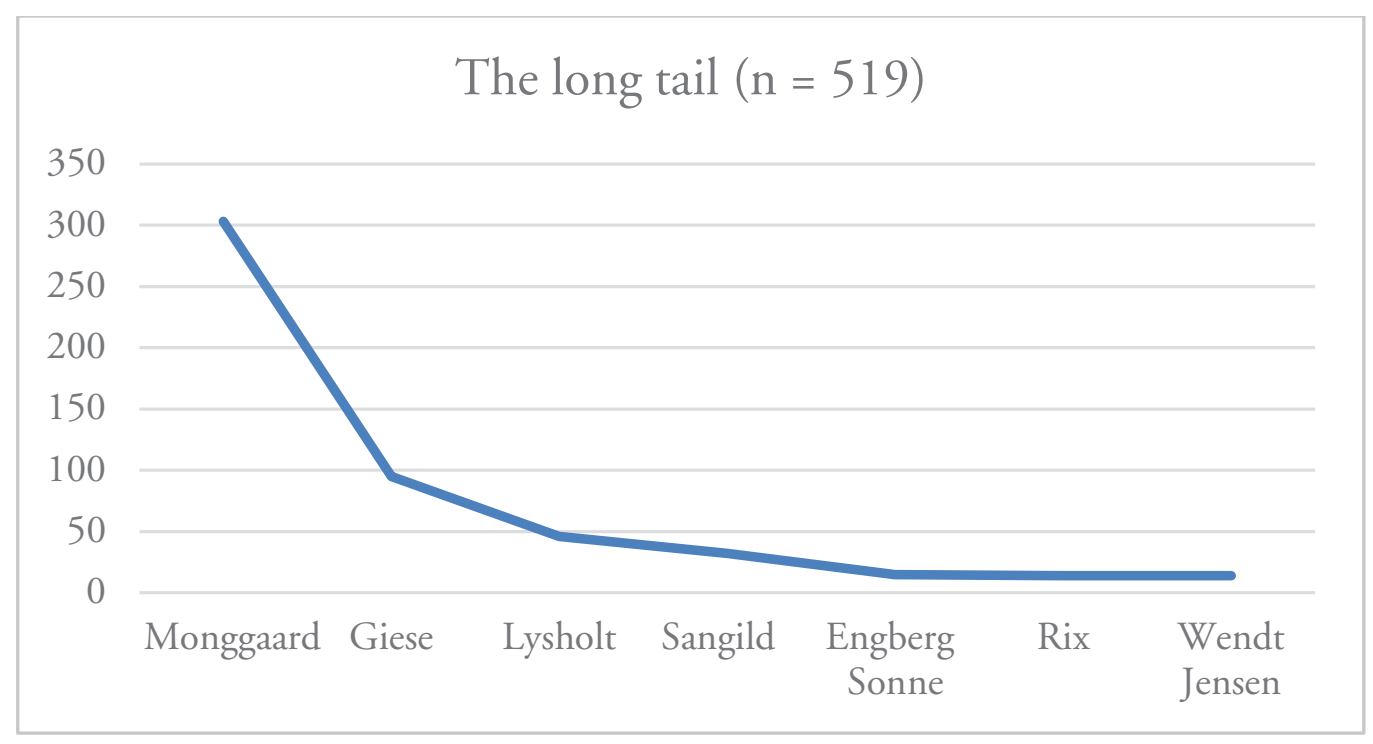

Figure 1: Distribution of number tweets/posts across the seven cases, absolute numbers

One case, Christian Monggaard, is very active (on Twitter), tweeting 22 times a day on average during the sampling period and representing the majority ( $58 \mathrm{pct}$.) of the posts/ tweets. Even though this skews the data, it makes him an interesting case. The second most active case, Ditte Giese, posts or tweets seven times a day during the sampling period. These two cases will therefore often serve as qualitative examples to illustrate how especially very active users circulate cultural content and tastes. ${ }^{5}$

The sampling period ran from midnight (00.00) Monday August 15, 2016 to midnight (23.59) Sunday August 28, 2016. This period represents an average two-week period without any significant cultural or political events to skew the data. The data set includes a total of 519 tweets and posts, 170 of which were original posts/tweets by the seven cases, while the remaining were re-circulations (with or without added comments). Thus, the sample is smaller compared to the very large data sets in a lot of the existing research. However, as argued by Hanusch and Bruns (2017, p. 39), specific journalists can serve as important nodes in social networks and are therefore important to study. 


\section{Archiving and coding}

During the archiving process, the empirical data are stabilised (Brügger, 2005; Lomborg, 2014), which can be done in numerous ways. We used the software Web Snapper, which archives the profiles within a given time period (backwards) and makes date and time, posts and tweets, comments, pictures and links become visible as they appear on Twitter or Facebook at the time of the harvest. That is, the software provides an accessible corpus of data. However, the harvested data can never provide the full picture of the communication, as the "dimension of reading and clicking through other social media profiles is simply lost" (Lomborg, 2014, p. 84). Videos, for example, cannot be accessed by means of Web Snapper archived data. The data were archived between August 30 and September 32016 by a research assistant.

Inspired by existing research on journalists on social media, cultural journalism and conversation analysis, we developed a codebook to analyse both Facebook posts and Twitter tweets (Steensen, 2014). The codebook focused on, for example, the origin of the communication (own post/tweet or retweet); the network or link structures (use of \#, @, links, etc.); the types of network (to own or other media or to non-media institutions); and the topic of posts/tweets (culture, lifestyle, sport, economy, politics and everyday life). A research assistant coded the posts/tweets in January 2017. Ten percent of the sample (from all sampled cases) was used in an intercoder-reliability test that showed a satisfactory intercoder reliability of 0.85 to 1.0 on most variables. ${ }^{6}$

\section{Analysis}

As indicated by the research overview, international research has shown that social media, especially Twitter, are gaining increasing influence in newsrooms, but also that "journalists and their employers are still trying to figure out best practice on the platform" (Hanusch \& Bruns, 2017, p. 39). The following analysis shows, first, that in Danish cultural newsrooms, the use of social media is still fairly random or sporadic. Only in a few cases does the use seem to be more systematic and conscientious. This points to quite diverse practices characterized by differences rather than commonalities. Second, the journalists' use of social media display quite blurred boundaries between institutional interests and professional identities, and more private interests and personal identities. The following analysis emphasises four areas where these blurred boundaries become particularly visible: 1) institutional strategies for use of social media; 2) topics and content being communicated and shared; 3) professional and personal promotional performances; and 4) use of communicative genres and tone. The first part of the analysis thus applies an institutional or meso-analytical perspective to the use of social media, drawing mainly on the interview data. The remaining part of the analysis focuses more on the actual practices of cultural journalists on social media, i.e., applies a micro-analytical perspective, based on the content analysis and qualitative exemplifications. Tweets/posts included to illustrate 
analytical arguments are translated from Danish to English. As media systemic circumstances and journalism cultures differ across countries, the analytical arguments apply primarily to the Danish context.

\section{Social media practices from an institutional perspective:}

\section{'Freedom with responsibility' and potential branding value}

International scholarship has pointed to the proliferation of social media among journalists. The use of social media among Danish cultural editors or journalists is still an emerging practice, however. Danish news media have neither clear ideas nor formalized strategies for the employees' social media use.

Most of the interviewed cultural editors do not have social media profiles for professional purposes. Some use social media in a personal/private context but most do not wish to share their personal lives with audiences as part of their professional practice. In that sense, they are not role models for their journalists in terms of an active social media use. Still, all editors say that journalists associated with their newsroom are free to be present on social media as they have freedom of expression. This freedom comes with a responsibility, though. The performances of the seven analyzed cases indicate that they all respect this "freedom with responsibility", as none of them communicate content in the analyzed period that would be considered transgressive in a Danish context. Accordingly, some editors explicitly state that they do not find policies necessary.

The editors do have varying practical and ethical interpretations of institutional expectations of journalists' social media behavior, however. At some newspapers, there is an institutional expectation of synchrony between the interests of the newspaper and the journalists' communication on social media as professionals and in a more private setting. Institutional interests come first. At other newspapers, personal boundaries are considered more important than institutional interests, and the practicing of journalism is considered a job rather than a personal dedication. Journalists' right to privacy, also on social media, is at the center.

Although the cultural editors themselves are less active on social media, they indicate that many journalists and critics affiliated with their newsroom have social media accounts used for both professional and personal types of communication. This is also exemplified by the seven cases. Especially cultural editors from print and online newspapers acknowledge the potential of social media for media institutional and personal branding purposes and, not least, for reaching younger audiences. This potential remains unexploited, however, since social media practices in a professional context continue to be an endeavour driven mainly by individual journalists. One of our cases, film editor and journalist Christian Monggaard from the niche newspaper Information, is an extraordinary example of this, as he has been very active on Twitter since 2009.

Journalists with a strong personality are seen as very attractive to the media institutions if they have exceptional professional merits, a strong network among other journal- 
ists and cultural industry professionals, or a strong charisma on social media resulting in many followers. When hiring journalists for new positions, it is, at some newspapers, seen as important to know if applicants are willing to invest extra efforts in being visible on social media. This required attractiveness has historical links as the cultural field has always been associated with charismatic personas with subjective and critical voices, and with strong ties between journalism and the cultural scene (e.g. Chong, 2017; Kristensen, 2017; Kristensen \& From, 2011). In other words, it links to the cultural mediator network feature, which is a "trademark" of cultural journalism potentially intensified by social media. This network feature, however, addresses a key challenge in terms of "liquid boundaries of work and off-work, work and play", as phrased by Hedman and Djerf-Pierre (2017: 423). This may not be unique to cultural journalists, but it may be particularly pronounced in this professional sub-group. As many cultural journalists and critics work freelance and have a loose coupling to specific news institutions, a constant social media presence of both a professional and personal nature may be indispensable.

At this stage, another media institutional difference becomes apparent: Editors affiliated with (print/online) newspapers see the potential for a more strategic use of social media to promote individual journalists. Editors from the public service institution $D R$ emphasise the importance of social media for promoting particular programs and content, as personal brands should not overshadow the institutional brand. This suggests that the latter group has a relatively traditional marketing approach to the use of social media rather than exploiting the logics of social media for personalised professional branding.

Overall, the interviews point to diverse approaches to the use of social media, which may not be distinct for this beat but do suggest that a "normalization" has not yet occurred in Danish cultural newsrooms. In the following, we apply a more micro-analytical perspective to demonstrate what the journalists share and how they communicate on social media.

\section{Blurring boundaries: Communication about culture - and other things}

All the analysed cases use social media to communicate and share content about cultural topics, and a large share of posts and tweets concerns cultural issues (46 percent in total). This signals that the journalists' professional domain heavily influences what they communicate about on social media?

The posts address culture in different ways. One type of cultural content highlights particular artists, works or events, for example, when journalists tweet or post about their own professional cultural articles, published by the news institutions they work for. Two examples are from Torben Sangild: "I have written about The Yes Men, surveillance Edward Snowden at the Roskilde Festival: kunsten.nu/journal/naar-p... \#kunstdk", and "Why is Louis C.K. (perhaps) the best comedian in the world? I provide the explanation zetland.dk/historie/sOX10... \#standupdk \#comedydk". This exemplifies that the traditional gatekeeping and marketing roles of cultural journalists are also present in their com- 
munication on social media, even though the idea of journalists as gatekeepers has been contested in the recent scholarly debates about journalism in a digital media landscape (e.g., Bro \& Wallberg, 2015). In such posts/tweets, the journalists draw on their institutionalised authority as professional journalists when bringing attention to cultural issues, goods or artists, and when ascribing them cultural value.

At times, the cultural content circulated is coloured by the journalists' personal tastes and preferences, confirming that social media communication is "driven by personal authorship" and therefore "content necessarily reflects the issues that concerns the authors" (Lomborg, 2014, p. 130). Christian Monggaard, for example, tweets: "Have, thanks to a good friend, discovered the world's best podcast - for comic book fans and collectors of all sorts: @FelixComicArt. Am extremely enthusiastic". In such cases, the journalist performs more as a gatewatcher (Bruns, 2003) by directing attention to cultural information sources outside their professional media institutional setting. This again illustrates the quite blurred boundaries of the cultural journalists' professional role, associated with cultural and institutional authority, and their more private, cultural predilections. This is because the legitimacy of such personal endorsements heavily relies on the journalists' privileged position in the cultural information circuit and their cultural capital/ authority as cultural journalists.

Other culturally focused tweets and posts are typified by their entertaining, anecdotal content. Christian Monggaard, for example, tells a story about Monty Python by means of four successive tweets:

\footnotetext{
"Heard the other day at BBC a funny story about Monty Python: It was in the 70s. Python was on a tour in the States and stayed at a hotel, where rock stars..."

"... often stayed. At the hotel, they were used to the guests trashing their rooms. Actually, they wanted more of that. It was good publicity."

"When they left the hotel, Python had not trashed anything, which the hotel manager found regrettable. He encouraged them to do it. They did not want to."

"But the hotel manager insisted, and at last Michael Palin went to the bathroom and broke a tooth brush".
}

Such cultural content or utterances mirror the conversational style of social media communication and exemplify cultural journalists playing with the social media conventions. At the same time, they confirm that cultural storytelling can in itself provide cultural experiences or entertainment (Kristensen \& From, 2011).

Finally, some posts and tweets connote celebrity-or gossip-like content as they display the cultural and personal networks which the journalists are part of. Christian Monggaard, for example, tweets about the $50^{\text {th }}$ birthday celebration of a fellow film critic, Jacob Wendt Jensen, from a competing news institution: "A well-dressed birthday boy @wendtjensen, welcomes at his round birthday. pic.twitter.com/2dr6Y4SO4P." 
The posted cultural content thus mirrors more traditional types of content in cultural journalism, but also shows how social media communication frames culture in new ways. Furthermore, it illustrates the quite blurred boundaries of the cultural journalists as professionals and private individuals.

Politics and everyday life/lifestyle issues also blend into the "conversations", i.e., issues relating more to a subjective political positioning, the private sphere and personal interests. Not surprisingly, this mix is most explicit in the communication of the most active cases, especially Christian Monggaard and Ditte Giese, who engage with a variety of topics (figure 2). While Monggaard's communication is dominated by cultural topics, including references to French artist Jacques Tardi, House of Cards, Monty Python, and a documentary on Shakespeare, he also tweets about sports (e.g., handball and cycling), politics (e.g., Donald Trump) and his private life (e.g., his 18 years old daughter). This diversity displays not only that he is a cultural omnivore (Peterson \& Kern, 1996) with a taste and appreciation for both elite culture and more popular genres. It also exemplifies his mix of professional/cultural interests, political opinions and private life matters. More politicised topics dominate Ditte Giese's communications. During the analysed period, she was involved in a heated debate involving an NGO working to protect the interests of single fathers. This debate links to her broader engagement in gender issues, especially feminism, i.e., to a more anthropological interpretation of culture. This signals that the blurred boundaries between culture, politicised issues and everyday life, known from cultural journalism in institutionalised news media (Riegert et al., 2015), resurface in some of the cultural journalists' activities on social media. ${ }^{8}$

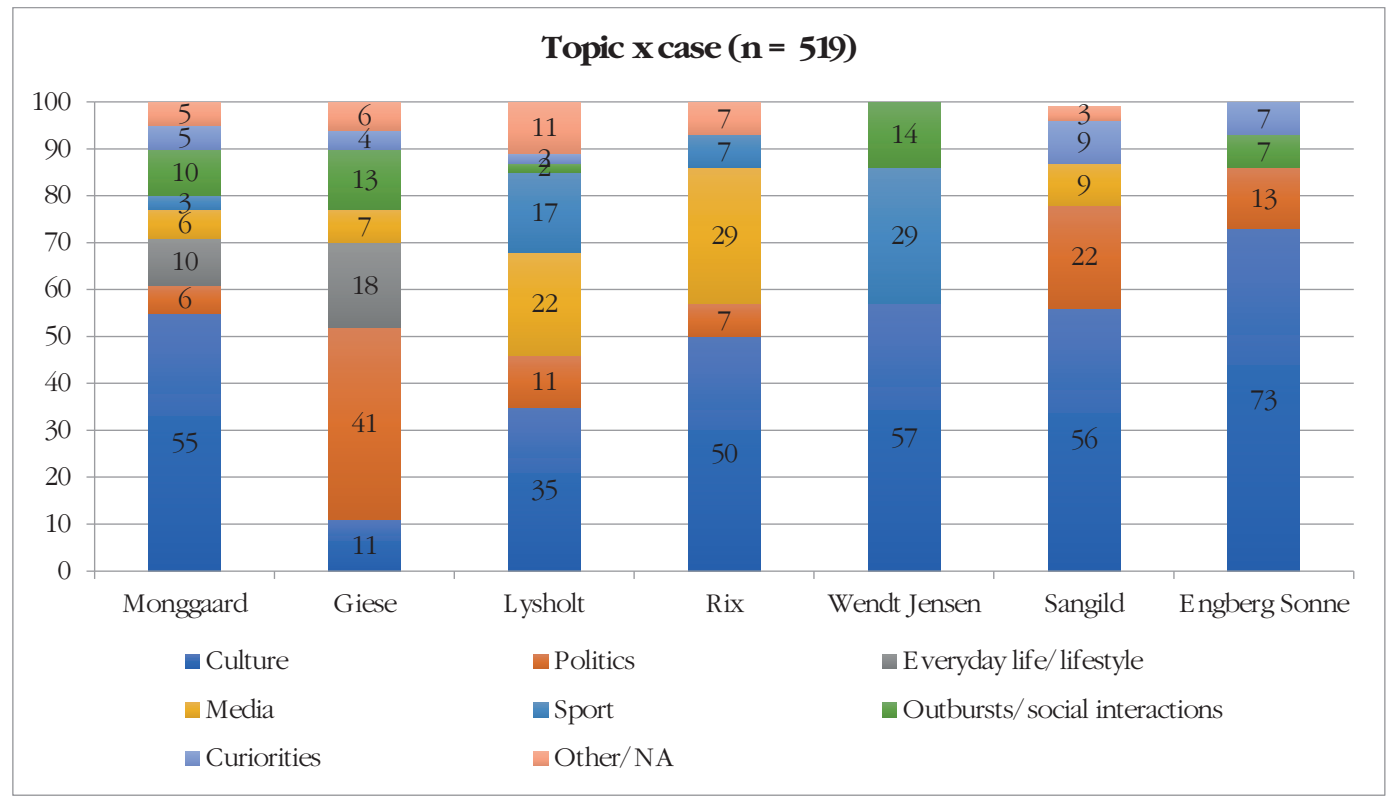

Figure 2: Topics of posts/tweets (in percentage of each case's number of posts/tweets) 
Overall, the data exemplifies individualised ways of articulating, distributing and sharing quite specific or distinct types of (cultural) content on social media, thus reflecting the journalists' professional interests and personal tastes. This merging of the professional and the personal complies not only with the logics of social media but also the logics of the cultural beat. That is, logics which have historically been characterised by a personalised (interest-based) selection of topics and opinionated approaches, allowing for, or requiring, the expression of the tastes and positions of the individual cultural journalist (e.g., Chong, 2017). Collectively, the cases represent an inclusive interpretation of and approach to culture - from publicity-like promotion of cultural products, tastes and events, over celebrity- or fan-like communication on cultural personas and colleagues to more politicized issues associated with culture as a "whole way of life" (Williams, 1958). As the following part of the analysis shows, the sharing of content also serves as promotion of the journalists' personalised professional brands.

\section{Blurring boundaries: Social media use for professional self-promotion}

Research on journalists' use of Twitter shows that tweets often promote the journalists' professional work or work produced by their colleagues. Molyneux (2015, p. 931) defines personal branding on Twitter as "any tweet that is self-referential, be that a notice of an upcoming television appearance, a link to one's own story, or positive and negative discussion of oneself".

Among political journalists, social media are used to circulate journalistic stories (Molyneux, 2015). The interviewed cultural editors in our study also point to this feature as important. Thus, it is not surprising that most of the seven cases use social media to promote their professional work or the professional work of the media institution they work for.' Some cases share this content without adding personal comments. Lars Rix, for example, mainly preannounces stories about cultural events and personas, i.e., circulates cultural news from Berlingske, where he was cultural editor at the time, and from other cultural news media. This exemplifies a more one-way-directional and (professional) promotional mode of communication rather than a dialogical, personal and informal approach, i.e., an approach that differs quite markedly from the communicative logic of social media. By contrast, Giese promotes her colleagues' and her own work by reframing posts and tweets with a personal comment: "Thanks to @LisbethBPoulsen @PSkipperEL @Gleesburg and all the other clever women in this politiken.dk/indland/ECE334... \#samtykke \#aldrigdinskyld". Moreover, the journalists share endorsements of their work from people in their network. In such cases, professional content is reframed (Hermida 2017, p. 411) by means of an added, personal comment, or by means of re-circulated endorsements.

Other promotional strategies seemingly provide insights - or transparency - to the journalistic production processes and the cultural establishment that the journalists mingle with as part of their professional work. Monggaard, for example, provides 
this line of tweets: "Interview with @KCornCoop submitted. Now Florence and after that @CphTvFestival and talk with Jay Carson, political consultant at @HouseofCards.", "Back at @CphTvFestival. Today I am talking to, among others, the people behind @MakingAMurderer. pic.twitter.com/JhD2n939MD" and "My interview with @KCornCoop about The New Yorker Presents is online (costs $\$ \$$ ): information.dk/ kultur/2016/08...." These examples illustrate Monggaard's broad network and professional relations with international cultural producers and celebrities from the film and television industry. By positioning himself as part of a network of cultural personas, he implicitly displays himself as a cultural brand and semi-celebrity. This implies that he uses a combination of professional skill as a cultural journalist and his own and others' public wellknownness to gain authority.

Hedman and Djerf-Pierre (2017, p. 423) argue that the transparency that goes hand in hand with a personalized use of social media among journalists increases the risk of threats and abusive comments. Molyneux (2015) in fact found that political journalists also tweet or retweet such negative comments or hate mail received on Twitter. Our sample includes very little of this type of interaction. This suggests a potential difference between political and cultural journalists' ways of communicating and (re)circulating content, as this is characterized by a positive tone and an amicable spirit among a loyal cultural community.

\section{Blurring boundaries: Decontextualised and cordial communication}

Research has pointed to the personal and verbal nature of the communicative genres used on social media. Lomborg describes the communication, especially on Twitter, as mainly phatic, cheerful, spontaneous, situated in the 'here-and-now' and characterised by liveness (Lomborg, 2014, p. 183). Furthermore, she describes the conversational environment as "noisy" (ibid., p. 113), at least for outsiders trying to study or track conversations. Tweets may appear esoteric or de-contextualised. This is also characteristic of the communication in our cases. One in ten tweets or posts did not address a specific topic nor did it have any meaning per se. They were mainly social interactions or private outbursts out of context, or conversations taking place elsewhere, in or outside the mediated space. See figure 3 for a few examples from our most active cases.

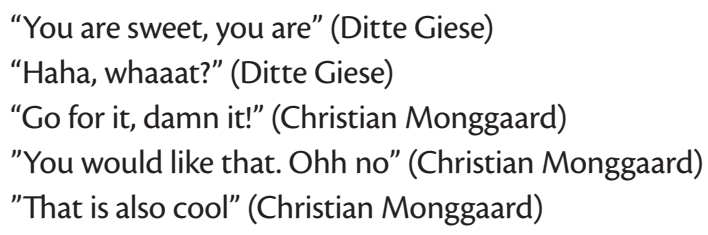

Figure 3: Examples of decontextualized posts/tweets 
Several of Monggaard's and Giese's tweets are such esoteric social interactions or spontaneous outbursts, or in medias res communications. In some cases, they seem to communicate with someone but not necessarily as part of a twitter-thread. In other cases, their posts/tweets do not appear to be intended for a response from their network. That is, they are more 'comments to self' but still mediated. The imagined receiver of the posts is conceived as 'an allied' or 'an insider', as someone who understands the in medias res communication without being provided any context. Monggaard, for example, tweets: "I too rarely wear a white tie and an opera hat" without providing any context for this statement.

The data confirms Molyneux's (2015) finding that humour is a communication strategy often deployed by journalists on social media. This suggests an adaptation to the logics of social media, which, to some extent, challenges the norms of journalism. The sample included several posts/tweets that were merely funny statements or jokes, coded as "curiosities", thus confirming the cheerful and informal tone of the platforms. ${ }^{10}$ This demonstrates how the (cultural) content is wrapped in very personal communicative styles characterized by spontaneity. That is, content which is part of a specific situation (Lomborg, 2014). This, paradoxically, means that the distribution, circulation and sharing of (cultural) content on social media are characterised by strategic personal and professional promotion and by a spontaneous, oral and a somehow non-strategic communicative style.

\section{Conclusion: Confirming existing and pointing to new intermediator roles}

Tapping into the current boom in research on journalists' use of social media, this article set out to investigate cultural journalists' social media use. The research literature argues that cultural journalists are "journalists with a difference", as they have long practiced a role of cultural mediators and worked in a grey zone between objective reporting and more personalised, subjective modes of communication. In that sense, the logics of social media and the logics of cultural journalism seem to complement each other well.

Our study concludes that the use of social media in (Danish) cultural newsrooms is still a quite random practice. From an editorial point of view, social media have great potential for institutional and personal branding, because they serve as platforms for circulating cultural stories, promoting cultural content and reaffirming cultural personas. However, cultural newsrooms do not yet have strategies and policies to support this strategically, nor do they set clear boundaries between professional and private social media communications. Such policies are not found necessary at this point, and they are also found difficult to formulate and implement. Use of social media has thus not yet been normalised among cultural journalists, despite social media logics and cultural journalism logics complementing each other well. The individual journalist is still the driving force on social media, resulting in quite different practices, as exemplified by the seven cases included in this study. 
Most use social media quite moderately, while few use the platforms more consistently or even intensely. Thus, the cases reflect the span in journalists' social media use more generally, pointed to by Hedman and Djerff-Pierre (2013). That is, the span between "the pragmatic conformists", who use social media cautiously and selectively, and "the enthusiastic activists", who lead an active or even extreme media life online (Hedman \& DjerffPierre, 2013, p. 382). In that sense, cultural journalists are not so different from other types of journalists. Several of the cases, especially the two heavy users of social media, Christian Monggaard and Ditte Giese, do indicate the potential of cultural journalists' social media use for media institutional branding and for self-branding purposes. They brand the media institution they work for by means of their personalized professional image and style of communication on social media. At the same time, their media institutional anchorage provides them with public visibility and a voice within institutionalized frameworks. Their legitimacy in the social media landscape is thus related to their professional authority as well as their personalised brand, which converge in their use of social media.

Despite quite diverse practices among cultural journalists on social media, a common denominator is culture as the dominating focus of posts and tweets. Together the cases represent an inclusive interpretation of culture and exemplify that cultural journalists perform cultural mediator roles, also on social media, by serving as gatekeepers, marketers, networkers and legitimizers. Thus, the social media practices of cultural journalists seem to amplify patterns known from their professional journalistic practices as "journalists with a difference", but these patterns have gained an even more personalised layer.

\section{Notes}

1 Barnard (2016) points to eight different types of practices via social media: information collection, news dissemination, sourcing, public note-making, public engagement, journalistic meta-discourse, other professional (inter)actions, and personal (inter)actions. His typology is thus most rich and finegrained in terms of journalists' professional uses of social media, but less so in terms of personal uses.

2 See, however, Cozma and Chen (2013) on foreign correspondents on Twitter, and Sheffer and Schultz (2010) and English (2016) on sports journalists on Twitter.

3 Similarly, Tandoc and Vos $(2016,961)$ ask "to which norms are journalists normalizing", arguing that journalists normalise more to the conventions of marketing than journalism, when using social media to push or market their own work.

4 Several interviewees have other positions in the media industry today, e.g., Lars Rix, Ditte Giese, Rune Lykkeberg, Anna von Sperling and Morten Thomsen Højsgaard.

5 We have not anonymized the cases, as they are media professionals and their social media profiles are publicly available, see also Aior's ethical guidelines (https://aoir.org/reports/ethics2.pdf, last accessed February 20, 2018). The interviewees have had the opportunity to comment on those parts of the analysis that are based on their statements.

6 Variables with a too low intercoder reliability were excluded from the analysis.

7 The topical domination of culture is even stronger, when posts/tweets originate from the cases themselves, i.e. if looking only at the 170 'original' posts/tweets authored by the cases and excluding 
retweets/re-postings with/out comments (Monggaard: 63 percent, Giese: 8 percent, Lysholt: 57 percent, Rix: 78 percent, Wendt Jensen: 67 percent, Sangild: 62 percent, Engberg Sonne: 67 percent).

8 The day after ending our sampling, September 1 2016, Ditte Giese was appointed debate editor at Politiken. The political and critical engagement displayed in her social media behaviour reflects her professional transition at the time and her personal engagement in politicised but culturally-saturated issues. We have kept her in the sample after all, as her use of social media adds important nuances to the analysis.

9 Among the 170 posts/tweets originating from the cases, one in five (31) is about the cases' own journalistic pieces or their journalistic work process, while one in ten (14) promotes articles by colleagues from their own media institution.

10 Though many statements may be communicated in a sarcastic or humorous tone, some of them appeared more as jokes than as addressing particular topics or issues: Ditte Giese, for example, tweets: "Is it a coincidence that both the cantine at @Radio24syv and the cantine @politiken today serve crisp fried pork slices for lunch? \#mediapig/pork?"; and Monggaard tweets "What is the new contact-free credit card all about? My bank has for years withdrawn money from my account without contacting me". Though these statements, respectively, concern Danish media institutions and the bank sector it would be misleading to code them 'media' and 'economics', as they are jokes.

\section{References}

Barnard, S. (2016). 'Tweet or be sacked': Twitter and the new elements of journalistic practice, Journalism, 17(2), 190-207.

Baumann, S. (2001). Intellectualization and Art World Development: Film in the United States, American Sociological Review, 66(3), 404-426.

Bourdieu, P. (1984). Distinction: A Social Critique of the Judgement of Taste. London: Routledge.

Brems, C., Temmerman, M., Graham, T., \& Broersma, M. (2016). Personal Branding on Twitter, Digital Journalism, online first.

Bro, P. \& Wallberg, F. (2015). Gatekeeping in a Digital Era, Journalism Practice, 9(1): 92-105

Bruns, A. (2003). Gatewatching, Not Gatekeeping: Collaborative Online News, Media International Australia, 107(1), 31-44.

Brügger, N. (2005). Archiving Websites: General Considerations and Strategies. Aarhus: Center for Internetforskning, Aarhus Universitet.

Brügger, N. (2011). Web archieving - Between past, present, and future. In M. Consalvo \& C.M. Ess (Eds) The Blackwell Handbook of Internet Studies, 24-42. Oxford: Wiley-Blackwell.

Canter, L. (2015). Personalised Tweeting, Digital Journalism, 3(6), 888-907.

Canter, L. (2013). The interactive spectrum: The use of social media in UK regional newspapers, Convergence, 19(4): 472-495.

Carpenter, S., Kanver, D., \& Timmons, R. (2016). 'It's about Me', Journalism Practice, online first.

Chong, P. (2017). Valuing subjectivity in journalism: Bias, emotions and self-interest as tools in arts reporting, Journalism, online first.

Cozma, R. Chen, K. (2013). What's in a Tweet? Foreign Correspondents' use of social media, Journalism Practice, 7(1), 33-46.

Danish Agency for Culture (2016). Mediernes udvikling: Internetbrug og enheder, http://slks.dk/fileadmin/ user_upload/dokumenter/medier/Mediernes_udvikling/2016/Internetbrug_og_enheder/Internetbrug_og_enheder_2016_-_FINAL_TIL_UPLOAD.pdf 
Danish Agency for Culture (2017). Mediernes udvikling: Internetbrug og enheder https://slks.dk/fileadmin/ user_upload/dokumenter/medier/Mediernes_udvikling/2017/Internetbrug_og_enheder/FINAL_ Internetbrug_2017.pdf

Dijck, J.v. (2012). Culture of Connectivity. New York: Oxford University Press.

English, P. (2016). Twitter's diffusion in sports journalism, New Media \& Society, 18(3), 484-501.

Forde, E. (2003). Journalists with a Difference: Producing Music Journalism. In Cottle, S. (Ed.), Media Organisations and Production (pp. 113-130). London: Sage.

Golin, C., \& Cardoso, E. (2009). Cultural Journalism in Brazil: Academic Research, Visibility, Mediation and News Values, Journalism, 10(1), 69-89.

Hanusch, F., \& Bruns, A. (2017). Journalistic branding on Twitter, Digital Journalism, 5(1), $26-43$.

Harries, G., \& Wahl-Jorgensen, K. (2007). The Culture of Arts Journalists, Journalism, 8(6), 619-639.

Heikkilä, R., Lauronen, T., \& Purhonen, S. (2017). The crisis of cultural Journalism revisited. The space and place of culture in European newspapers from 1960 to 2010, European Journal of Communication, online first.

Hedman, U., \& Djerf-Pierre, M. (2013). The social journalists, Digital Journalism, 1(3), 368-385.

Hedman, U., \& Djerf-Pierre, M. (2017). Journalists' Use of Twitter. In Franklin, B. \& Eldrigde II, S.A. (Eds), The Routledge Companion to Digital Journalism Studies (chapter. 41, pp. 417-426). New York: Routledge.

Hellman, H., \& Jaakkola, M. (2012). From Aesthetes to Reporters: The Paradigm Shift in Arts Journalism in Finland, Journalism, 13(6), 783-801.

Hermida, A. (2010). Twittering the News, Journalism Practice, 4(3), 297-308.

Hermida, A. (2013). '\#Journalism', Digital Journalism, 1(3), 295-313.

Hermida, A. (2017). Twitter, Breaking the News, and Hybridity in Journalism. In Franklin, B., \& Eldrigde II, S.A. (Eds), The Routledge Companion to Digital Journalism Studies (chapter. 40, pp. 407-416). New York: Routledge.

Hovden, J.F., \& Knapskog, K. (2015). Doubly Dominated. Cultural Journalists in the Fields of Journalism and Culture, Journalism Practice, 9(6), 791-810.

Hovden, J.F., \& Kristensen, N.N. (2018). The Cultural Journalist Around the Globe: A Comparative Study of Characteristics, Role Perceptions and Perceived Influences. Journalism, online first: http://journals. sagepub.com/doi/10.1177/1464884918791224.

Jaakkola, M. (2015). The Contested Autonomy of Arts and Journalism: Change and Continuity of the Dual Professionalism of Cultural Journalism. PhD-dissertation. Tampere: University of Tampere.

Janssen, S, \& Verboord, M. (2015). Cultural Mediators and Gatekeepers. In Wright, J.D. (Ed), International Encyclopedia of the Social \& Behavioral Sciences (pp. 440-446). 2nd ed. Vol. 5. Oxford: Elsevier.

Jørgensen, J.C. (2007). Journalistik med stil. Ajour: Aarhus.

Kersten, A., \& Janssen, S. (2017). Trends in Cultural Journalism: The Development of Film Coverage in Cross-National Perspective, 1955-2005, Journalism Practice, 11(7), 840-856.

Knapskog, K., \& Larsen, L.O. (Eds) (2008). Kulturjournalistikk. Pressen og den kulturelle offentlighed [Cultural Journalism. The Press and the Cultural Public Sphere]. Oslo: Scandinavian Academic Press.

Kristensen, N.N. (2003). Journalister og kilder - sliger i valsen? [Journalists and News Sources - Is There a Glitch?]. PhD-dissertation. University of Copenhagen.

Kristensen, N.N. (2017) Churnalism, cultural (inter)mediation and sourcing in cultural journalism, Journalism Studies, online first: DOI: 10.1080/1461670X.2017.1330666.

Kristensen, N.N., From, U. (2011) Kulturjournalistik. Journalistik om kultur. Frederiksberg: Samfundslitteratur.

Kristensen, N.N., \& From, U (2015a). Cultural Journalism and Cultural Critique in a Changing Media Landscape, Journalism Practice, 9(6), 760-772. 
Kristensen, N.N., \& From, U. (2015b). Publicity, News Content, and Cultural Debate: The Changing Coverage of Blockbuster Movies in Cultural Journalism, Communication, Culture \& Critique, 8, 484-501.

Kristensen, N.N. \& Riegert, K. (Eds) (2017). Cultural Journalism in the Nordic Countries, Göteborg: Nordicom.

Lasorsa, D, Lewis, S. \& Holton, A. (2012). Normalizing Twitter, Journalism Studies, 13(1), 19-36.

Lomborg, S. (2014). Researching Communicative Practice: Web Archiving in Qualitative Social media Research. In Bredl, K, Hünniger, J \& Jensen, J.L. (Eds). Methods for Analyzing Social Media, (p. 78-90) London: Routledge.

Marwick, A. \& boyd, d. (2011). To See and Be Seen: Celebrity Practice on Twitter, Convergence, 17(2), $139-$ 158.

Marshall, D.P. (2014) Persona studies: Mapping the proliferation of the public self, Journalism, 15(2), 153170.

Molyneux, L. (2015) What journalists retweet: Opinion, humor, and brand development on Twitter, Journalism, 16(7), 920-935.

Olausson, U. (2017). The Reinvented Journalist, Digital Journalism, 5(1), 61-81.

Parmelee, J.H. (2014). Political Journalists and Twitter: Influences on norms and practices, Journal of Media Practice, 14(4), 291-305.

Peterson, R.A. \& Kern, R.M. (1996). Changing Highbrow Taste: From Snob to Omnivore, American Sociological Review, 61(5), 900-907.

Riegert, K., Roosvall, A. \& Widholm, A. (2015). The Political in Cultural Journalism: Fragmented interpretative communities in the digital age, Journalism Practice, 9(6), 773-790.

Sarrimo, C. (2016). The Press Crisis and its Impact on Swedish Arts Journalism, Journalism, online first. doi:10.1177/1464884915625629.

Sheffer, B. \& Schultz, M.L. (2010). An exploratory study of how Twitter is affecting Sports Journalism, International Journal of Sport Communication, 3(2), 226-239.

Steensen, S. (2014). Conversing the audience: A methodological exploration of how conversation analysis can contribute to the analysis of interactive journalism, New Media \& Society, 16(8), 1197-1213.

Sparre, K. \& From, U. (2017). Journalists as Tastemakers. An analysis of the Danish TV-series Borgen in a British, Swedish and Danish news brand. In Kristensen, N.N. \& Riegert, K. (Eds.), Cultural Journalism in the Nordic Countries, (pp. 159-178) Göteborg: Nordicom.

Subašić, I. \& Berendt, B. (2011). Peddling or Creating? Investigating the Role of Twitter in News Reporting. In: Clough P. et al. (Eds) Advances in Information Retrieval. ECIR 2011. Lecture Notes in Computer Science, vol 6611. Springer, Berlin: Heidelberg.

Tandoc, E. Jr. \& Vos, T. (2016). The Journalist is Marketing the News, Journalism Practice, 10(8), 950-966.

Vis, F. (2013). Twitter as a reporting tool for breaking news, Digital Journalism, 1(1), 27-47.

Williams, R. (1958). Culture and society. London: Chatto and Windus.

http://www.pewinternet.org/2015/01/09/social-media-update-2014/

http://www.pewinternet.org/2015/01/09/frequency-of-social-media-use-2/

Nete Nørgaard Kristensen Associate Professor

Department of Media, Cognition and Communication

University of Copenhagen

netenk@hum.ku.dk 
Article: Cultural journalists on social media

Unni From

Deputy Head of School

School of Communication and Culture - Media Studies

Aarhus University

imvuf@cc.au.dk 